\title{
STABILISING ROCK SURFACES WITH A GLASS REINFORCED POLYMER SKIN
}

\author{
Jan NEMCIK *, Ernest BAAFI and Ian PORTER
}

\author{
School of Civil, Mining and Environmental Engineering, Faculty of Engineering, University of Wollongong, \\ Northfields Avenue, Wollongong, NSW 2522, Australia \\ *Corresponding author's e-mail: jnemcik@uow.edu.au
}

(Received September 2012, accepted December 2012)

\begin{abstract}
Mine roadways developed in highly stressed strata are subject to roof shear, which under severe conditions may manifest as the well known symptom of guttering, particularly at the roadway edge leading into the major horizontal stress. This roof shear can progressively reduce the effectiveness of bolt confinement of the strata within the lower roof horizon affecting stability of the immediate roof. This paper presents the results of a study to investigate the effectiveness of polymers as skin reinforcement in highly stressed coal mine roadways, as they may provide better roadway skin support than the currently used steel mesh. A large concrete block intercepted with artificial joints and reinforced with steel bolts without skin support, was loaded until significant slip occurred along the joints. Upon loading, a roof cavity resembling a gutter developed, as some of the jointed concrete parted from the free surface. In addition to bolts, subsequent models with identical fracture planes were supported with steel mesh or with glass reinforced polymer skin bonded to the free side. Loads and displacements were compared for models with and without skin reinforcement. As expected the skin support helped resist gutter formation, to various degrees, while increasing the residual strength of the concrete block. It was found that there was significantly less bedding displacements in models with the polymer skin, when compared with both steel mesh and no skin reinforcement. This suggests that there would be benefits to using a spray on polymeric skin as surface support in roofs subject to severe roof shear.
\end{abstract}

KEYWORDS: bolts and anchors, TSL support, laboratory testing

\section{INTRODUCTION}

Steel mesh has been used successfully for many years to support strata and minimise loose material from falling into the mine opening. Current advances in the automation of roof bolt installation in underground mine roadways requires fast and efficient application of skin reinforcement. This suggests that the process of steel mesh installation needs to be automated, but this has proven to be difficult. To satisfy the above needs a strong and tough fibre reinforced polymeric alternative is emerging as a logical substitute to the old steel mesh support system. The application of these fast setting Thin Spray-on Liners (TSL) may be fully automated and have been proposed as a replacement for mesh.

To investigate the roof reinforcing mechanisms of the polymer thin spray on liner (TSL) for use in underground coal mines, a series of tests were undertaken to quantify the TSL's reinforcement capabilities when related to its thicknesses, strength, adhesion and ability to penetrate fractures. In order to provide effective reinforcement the spray-on glass reinforced polymer skin must have strong adhesion to the substrate forming a strong and tough composite layer. Various small and large scale laboratory tests were performed on several polymer formulations under development to enable selection of the most suitable TSL for substrate reinforcement. These laboratory tests are a precursor to full-scale underground trials.

\section{SUMMARY OF PREVIOUS TESTS}

Puncture tests of glass reinforced polymer liner were performed (Nemcik et al., 2011) using a series of steel discs to determine if the standard steel bolt plate system that is currently used underground may induce excessive stress concentrations onto the polymer TSL. Discs of various diameters were placed onto a $5 \mathrm{~mm}$ thick fibre reinforced polymer sheet and loaded until the polymer surface was compromised. The puncture tests using a $120 \mathrm{~mm}$ steel disc and standard bolt plates indicated that a $5 \mathrm{~mm}$ thick reinforced polymer sheet can withstand substantial loads up to $3300 \mathrm{kN}$ before permanent damage occurred. These tests indicated that the commonly used design of steel bolt plate may not need to change, however, it should be noted that these puncture tests were performed on perfectly flat surfaces that rarely exist underground.

In addition to the puncture tests, destructive loading of a $5 \mathrm{~mm}$ thick TSL was undertaken to determine the ultimate strength of the reinforced polymer sheet (Nemcik et al., 2011). This series of 


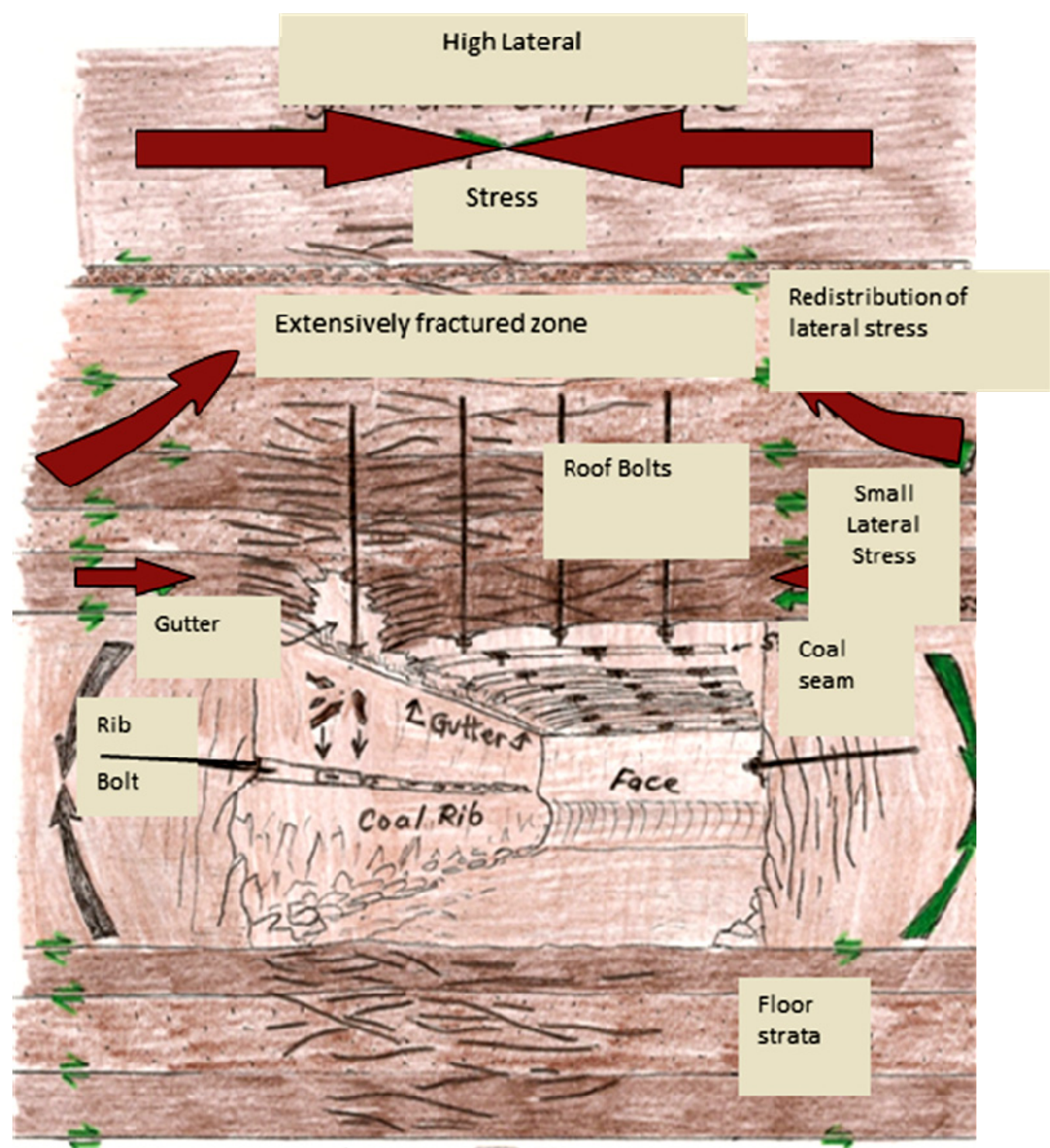

Fig. 1 Typical roof conditions in coal mine roadway in a high lateral stress environment.

tests indicated that the polymer is tough and strong, capable of carrying large dead loads ranging from $45 \mathrm{kN}$ to more than $100 \mathrm{kN}$ depending on the load distribution between the bolts. The load distribution plays an important role in the polymers apparent strength. The TSL's tested appear to be comparable in performance to the heavy duty steel mesh commonly used in the Australian coal mining industry.

A numerical model was used to study effects of the TSL adhesion to a substrate. The models indicated that even a small degree of adhesion would have a positive influence on overall roof support. The simulations also indicated that strong adhesion makes the polymeric liners superior to the passive steel mesh. Benefits of the polymer skin can arise from the ability to adhere well to rock/coal surfaces and provide significant resistance to strata displacements and fracture opening. The reinforced polymer skin is fundamentally a different type of support to the passive steel mesh, providing early resistance to any movement as soon as movement begins to occur. Localised de-bonding of the polymer from the rock surface during fracture movement is unavoidable but does not significantly affect the polymer reinforcing capabilities. The experimenal data also indicate that in-situ rock roughness enhances the adhesive properties of the polymer skin and can be harnessed to play a useful role in strata skin reinforcement.

\section{COMPARING THE SKIN SUPPORT CAPABILITIES OF GLASS FIBRE REINFORCED POLYMER AND STEEL MESH ON CONCRETE BLOCKS WITH SIMULATED FRACTURE PLANES}

In a high lateral stress environment mine roadways can sustain significant roof and floor damage if oriented at a high angle to the maximum horizontal stress. Roof tends to develop gutters (cutter) on the side of the roadway when severely damaged and unsupported rock falls out (Figure 1). 


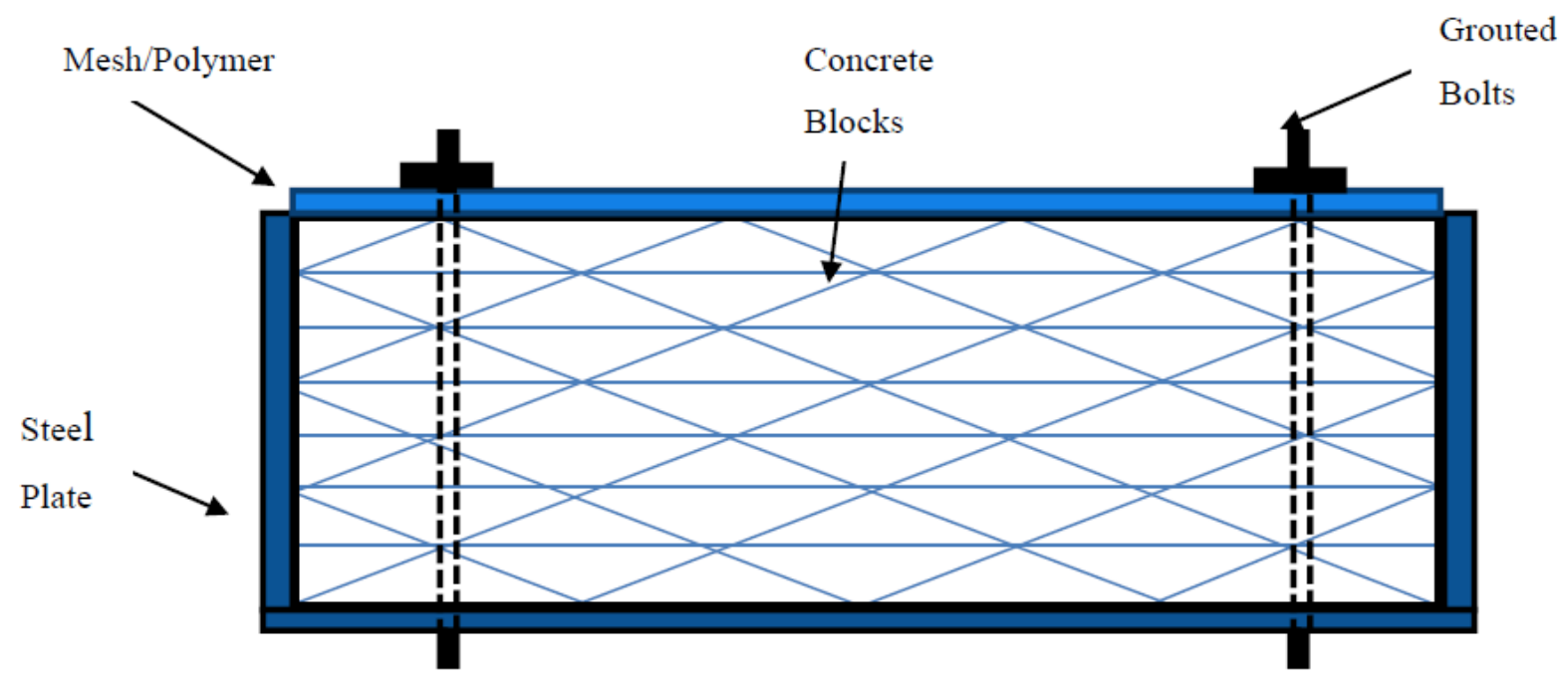

Fig. 2 Test specimen assembled from concrete prisms to imitate fractured strata.
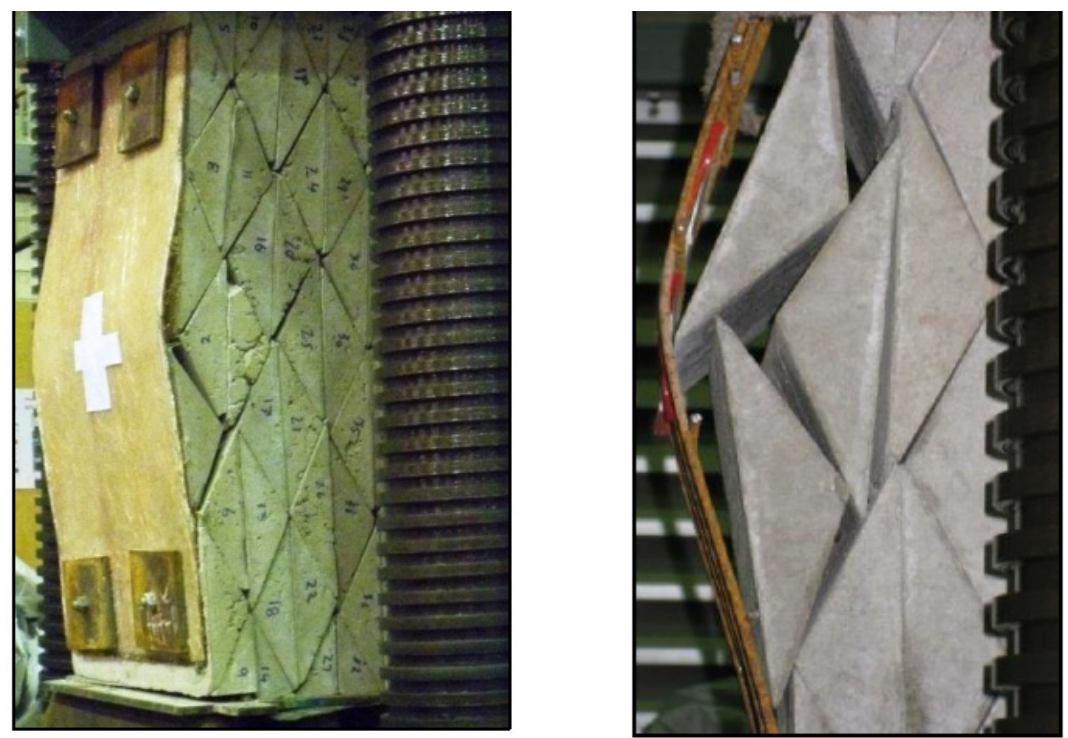

Fig. 3 Loading of the concrete specimen reinforced with polymer sheet showing dilation of the concrete prisms.

To assess the reinforcing capabilities of glass reinforced polymer skin supporting damaged sedimentary strata a $5 \mathrm{~mm}$ polymer layer was bonded to a concrete block formed from a number of small triangular prisms to simulate fractured strata. The concrete prisms within the block were oriented as shown in Figure 2 to simulate failed bedding planes and low angle shear fractures that often form in response to high lateral stress.

Three of these large scale tests were conducted. In addition to a test with no skin reinforcement, which produced predictable results, a second test used the glass fibre reinforced polymer for skin support and another used steel mesh. The block dimensions were restricted to $800 \times 400 \times 400 \mathrm{~mm}$ in size due to the loading machine size. The three sides were confined with steel plates and bolts while one side was a free face reinforced first with the polymer reinforcement and then with the steel wire mesh. The $5 \mathrm{~mm}$ glass reinforced polymer sheet was bonded (using the same polymer) to the exposed concrete face to simulate adhesion of the sprayed polymer to the concrete prisms. The confined concreteblock was then mounted into the loading machine and loaded at a rate of $0.5 \mathrm{~mm}$ per minute, the load and displacements were monitored.

As the load increased the slip along the concrete prisms dilated the concrete loading the reinforcing polymer sheet. The polymer sheet gradually debonded but continued to resist the substantial concrete skin movement (Figure 3) with the maximum load and deflection shown in Table 1 and graphed in Figure 5. The test was stopped prior to polymer failure as unsafe conditions due to excessive block displacement were experienced. 
Table 1 Loading of concrete wedges supported with polymer skin.

\begin{tabular}{ll}
\hline Polymer skin support & Results \\
\hline Maximum load reached & $495.9 \mathrm{kN}$ \\
Maximum mesh deflection & $94.3 \mathrm{~mm}$ \\
\hline
\end{tabular}

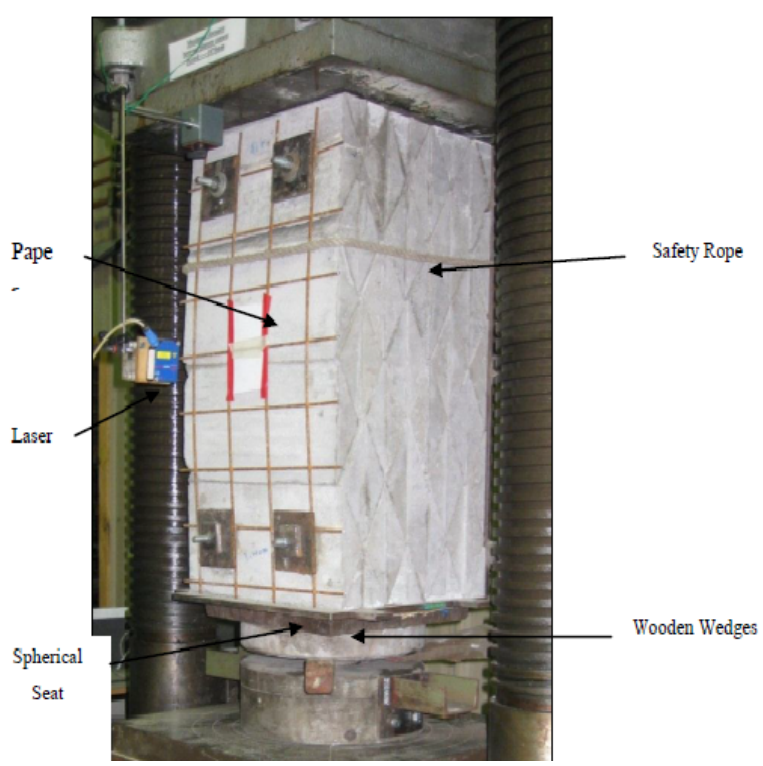

Table 2 Loading of concrete wedgessupported with steel wire mesh.

\begin{tabular}{ll}
\hline Steel mesh skin support & Results \\
\hline Maximum load reached & $248.3 \mathrm{kN}$ \\
Maximum mesh deflection & $107.3 \mathrm{~mm}$ \\
\hline
\end{tabular}

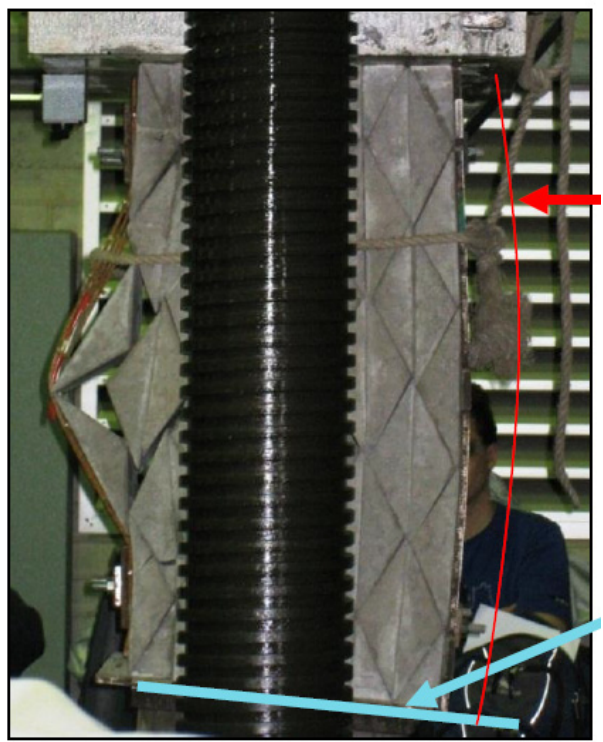

Fig. 4 Loading of the concrete specimen reinforced with steel wire mesh showing displacement and rotation of the prisms.

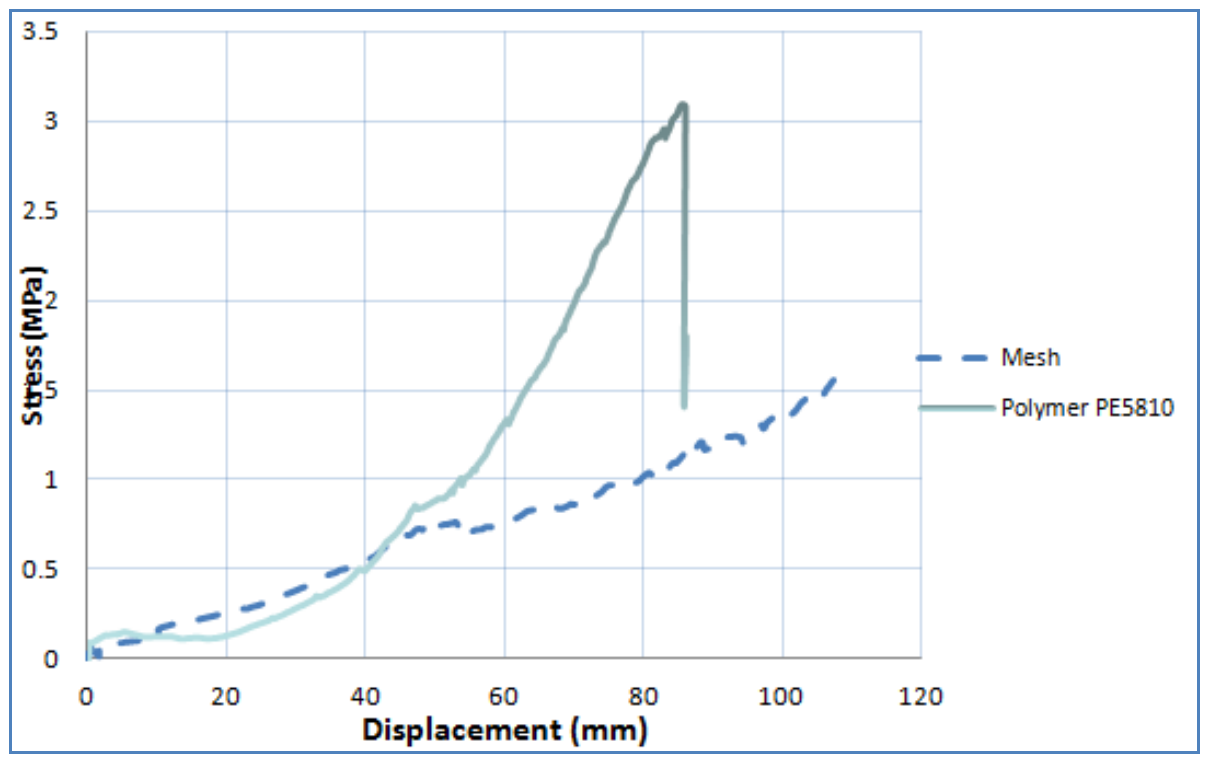

Fig. 5 Load vs displacement results for tested concrete specimen reinforced with the polymer skin and steel wire mesh.

To compare the effectiveness of the polymer skin reinforcement versus the steel wire mesh support, the experiment was repeated with $5 \mathrm{~mm}$ thick $100 \mathrm{x}$ $100 \mathrm{~mm}$ steel wire mesh attached to the concrete face with four bolts and plates. The concrete specimen was loaded at the same rate as before and the block behaviour monitored. The loaded specimen supported with the steel wire mesh is shown in Figure 4. As the load on the sample increased, the blocks began to slide along the discontinuities and rotate, displacing and loading the wire mesh. As before the test was not loaded to failure as the displacements of the specimen exceeded the safe limits. The maximum load and the associated deflection are shown in Table 2 and graphed in Figure 5. 
Table 3 Material properties from the laboratory tests used in the UDEC model.

\begin{tabular}{lccccc}
\hline Material & $\begin{array}{c}\text { Young's Mudulus } \\
E(\mathrm{GPa})\end{array}$ & $\begin{array}{c}\text { Bulk Modulus } \\
\mathrm{K}(\mathrm{GPa})\end{array}$ & $\begin{array}{c}\text { Shear Modulus } \\
G(\mathrm{GPa})\end{array}$ & $\begin{array}{c}\text { Poisson's } \\
\text { Ratio }\end{array}$ & $\begin{array}{c}\text { Tensile } \\
\text { Strenght }(\mathrm{MPa})\end{array}$ \\
\hline $\begin{array}{l}\text { Concrete Blocks } \\
\begin{array}{l}\text { (Gere 2010) } \\
\text { Reinforced Polymer }\end{array}\end{array}$ & 30 & 16.7 & 12.5 & 0.2 & - \\
$\begin{array}{l}\text { (Dear 2010) } \\
\begin{array}{l}\text { Low Carbon Steel Wire } \\
\text { (Lukey et al.) }\end{array}\end{array}$ & 1.952 & 2.16 & 0.72 & 0.35 & 52.6 \\
\hline
\end{tabular}
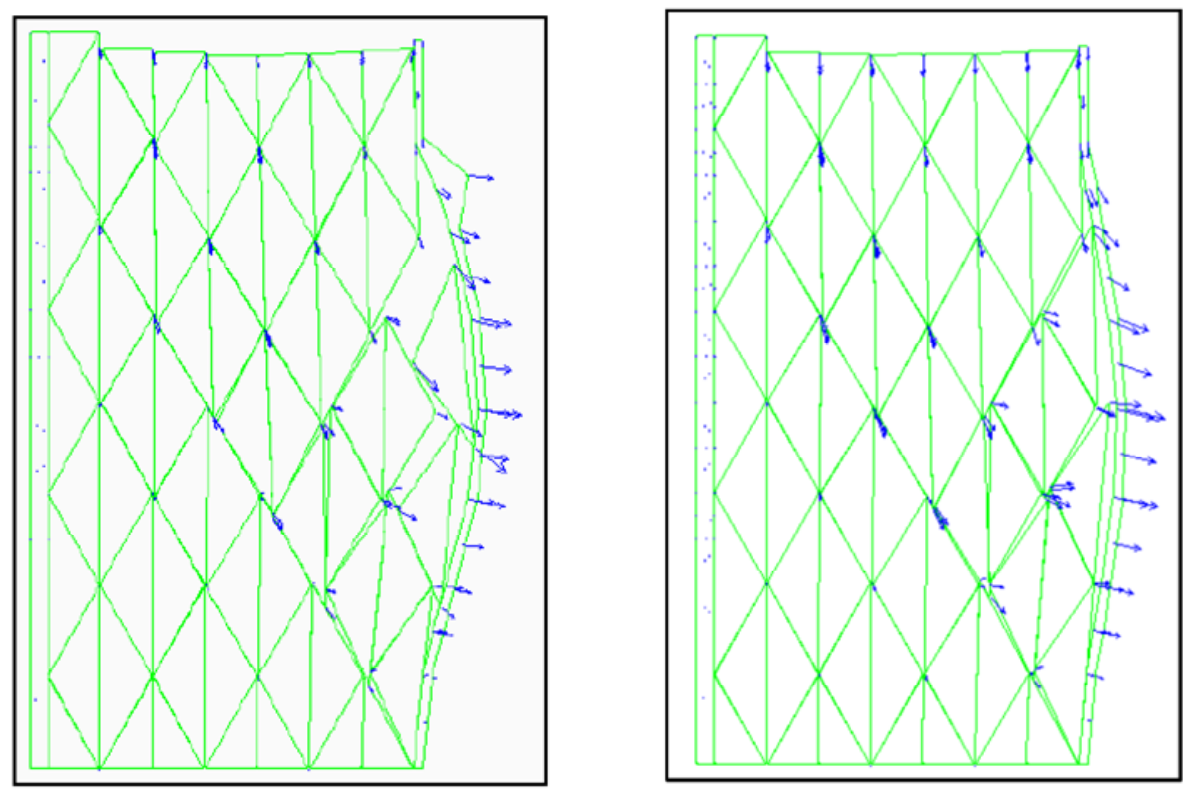

Fig. 6 UDEC model of a jointed concrete with the free face supported with (a) steel wire mesh, (b) glass reinforced polymer skin.

\section{NUMERICAL MODEL}

The experimental testing was simulated using the Universal Distinct Element Code (UDEC) to further evaluate the influence of steel mesh and polymer reinforcement on skin support. The material properties used in the model are shown in Table 3.

The properties of steel mesh are very complex, as they are highly dependent on the direction in which the mesh is loaded. For the steel mesh sample, the modelled properties were adjusted to represent the percentage of the steel mesh actually covering the total surface area. The numerical models examined the steel mesh and the polymer surface support and its ability to confine the strata. The modelled block was positioned in the same way as the tested physical model. Graphical represntations of the loaded models are shown in Figure 6 (a) and (b) respectively.

The applied load versus the maximum displacement at the free face of each block is shown in
Figure 7. During the experimental stage the loose concrete blocks settled under gravity and induced in both cases an initial displacement of approximately $19 \mathrm{~mm}$. Since the perfectly aligned joints in the model did not show any initial displacement when gravity was applied, additional graphs with a $19 \mathrm{~mm}$ adjustment were plotted for comparison, shown as broken lines in Figure 7. These adjustments show better correlation with the laboratory tests.

The modelled results clearly support the laboratory experimental results and demonstrate that the glass reinforced polymer skin offers a stiffer support system.

\section{DISCUSSION}

The polymer sample deflected more than expected during the early stages of loading (Figure 5) probably due to early de-bonding of the polymer from the upper portion of the sample. The de-bonding 


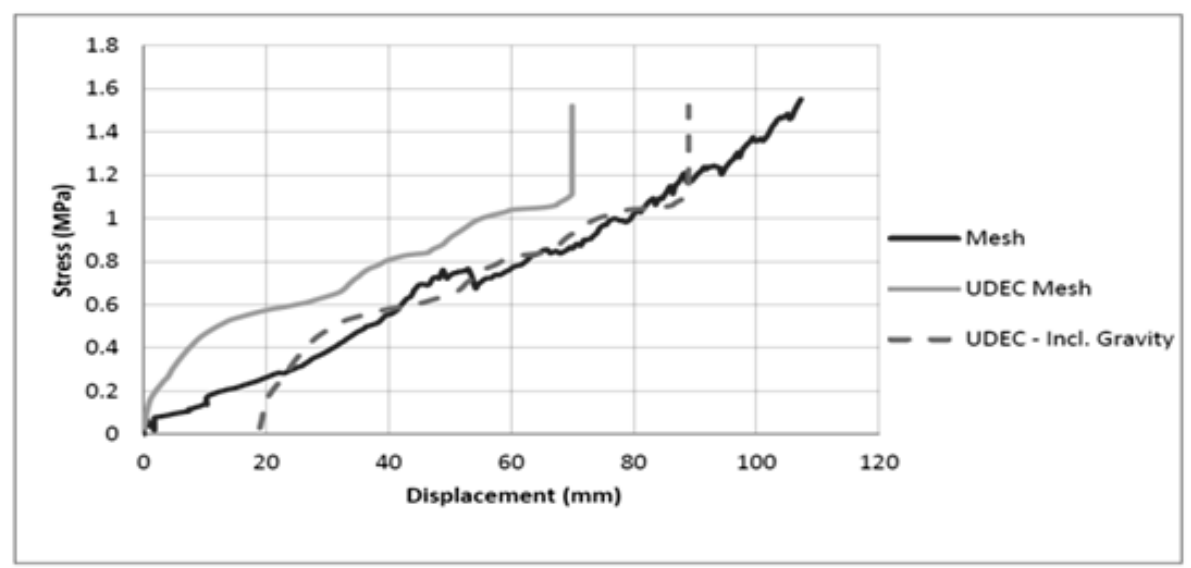

(a)

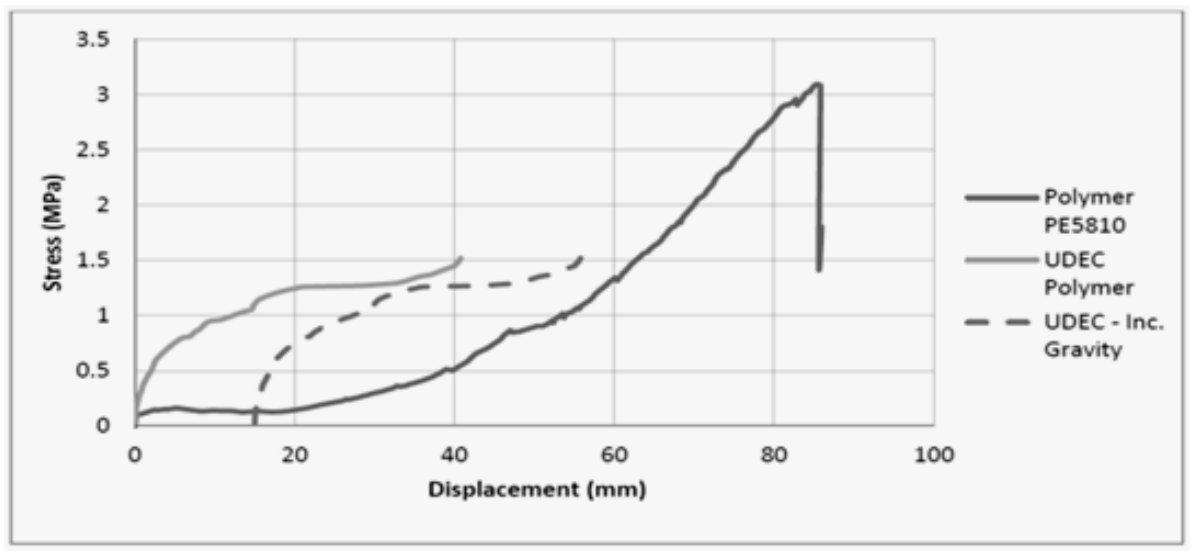

(b)

Fig. 7 Applied load versus maximum displacement at the free face of a block supported with (a) steel wire mesh (b) polymer skin.

occurred at a lower load than expected (approximately $25 \mathrm{kN}$ ) and possibly allowed the polymer to move more freely. Previous (different) tests indicated much better adhesive properties of the polymer skin to the substrate. The lower section of the polymer remained bonded to the concrete block much further into the loading as it was more easily able to rotate and move with the polymer. The total de-bonding of the polymer skin occurred at a load of approximately $260 \mathrm{kN}$, when the upper blocks began to displace and rotate considerably. The final deflection of the polymer and displacement of the blocks are shown in Figure 5 and Table 1.

When the steel mesh sample was loaded into the hydraulic press an initial deflection of approximately $19 \mathrm{~mm}$ was recorded mainly due to gravity. This provides a direct indication of the passive nature of mesh reinforcement. The most significant displacement was seen at the upper blocks that were not fixed by the rock bolts. As the loading on the sample increased, the blocks began to gradually slide along each other displacing and loading steel wire mesh. As the displacement increased, the concrete blocks at the mesh face began to rotate considerably
(Figure 4). As a result the mesh loading was essentially coming from a single point on the outer most blocks. The uneven loading caused the spherical seat located below the concrete specimen to rotate and contribute to uneven displacements.

On the whole, both the steel mesh and the polymer skin did not reach their ultimate strength as each experiment was terminated due to excessive movement of the concrete blocks and the unsafe conditions that occurred at the later stage of each test. The vertical unloading part of the curves that can be seen in Figure 5 and Figure 7 (b) represent unloading of the samples. The initial stages of load verse displacement for both tests indicate similar behaviour, however, at the later stage accelerated loading of the sample reinforced with the polymer skin was experienced.

Despite having the same specimen geometry in both tests, the interaction between the concrete prisms was not the same. Block displacement and rotation were larger in the steel mesh case and on the whole the polymer mesh appeared to control displacements better than the steel mesh. This led to larger loads with smaller skin displacements for the polymer 
samples, suggesting that the polymer helps the roof to maintain its integrity while the mesh allows softening at an earlier stage. Results from the numerical models support the laboratory experimental results and demonstrate that the glass reinforced polymer skin offers a stiffer support.

\section{CONCLUSION}

In order for polymer liner products to be regarded as a suitable replacement for steel mesh, the advantage of polymer reinforcement must be clearly demonstrated. Steel mesh provides only passive support to the substrate, while it is expected that a polymer liner would adhere to the substrate and act as composite with the rock. These tests demonstrated the concept of effective skin reinforcement, however early de-bonding of the polymer sheet was unsatisfactory indicating the possibility of inadequate preparation of the bonded surfaces. Previous polymer capacity tests (Nemcik et al., 2011) clearly demonstrated that the polymer has superior bonding characteristics that significantly improve skin reinforcement performance.

Polymer liners have the potential to replace steel mesh as the major form of surface support in underground coal mines. Results obtained from experimental investigations and computational models clearly establish that the tested fibre reinforced polymers are better than steel mesh in resisting skin displacements. The polymer has the ability to penetrate into fractures bonding adjacent fragments together and providing stiffer, more effective support. The polymer not only provides better resistance to rotation and deflection but can also sustain higher loads than the mesh. In addition to this, the polymer can bond satisfactorily to itself allowing fractures or damaged areas to be easily repaired.

\section{REFERENCES}

Nemcik, J., Porter, I., Baafi E. and Towns, J.: 2011, Bearing Capacity of a glass fibre reinforced polymer liner. 11th Underground Coal Operators' Conference, University of Wollongong \& the Australasian Institute of Mining and Metallurgy, 148-153.

Nemcik, J., Porter, I., Baafi E. and Navin, J.: 2011, Determining the ultimate strength of 'Tough Skin', a glass fibre reinforced polymer liner. 11th Underground Coal Operators' Conference, University of Wollongong \& the Australasian Institute of Mining and Metallurgy, 154-158. 